\title{
KEDUDUKAN ASET DARI YAYASAN YANG BELUM DISESUAIKAN PASCA TERBITNYA UNDANG-UNDANG NOMOR 28 TAHUN 2004 TENTANG PERUBAHAN ATAS UNDANG-UNDANG NOMOR 16 TAHUN 2001 TETANG YAYASAN
}

\author{
Mustofa Mustofa \\ Magister Hukum Universitas Semarang
}

\begin{abstract}
ABSTRAK
Penelitian ini bertujuan untuk menganalisa kedududkan aset yang belum disesuaikan setelah terbitnya peraturan terbaru mengenai yayasan. Keberadaan yayasan di Indonesia mempunyai kekuatan yang penuh dengan adanya Undang-Undang Yayasan yaitu Undang-Undang Nomor 28 Tahun 2004. Hal ini menimbulkan segala sesuatu yang berkaitan dengan aset yayasan baik yang bersifat materil maupun immateril harus disesuaikan dengan ketentuan yang berlaku. Apabila tidak disesuaikan, akan berakibat tidak diakuinya yayasan yang telah berdiri, sehingga pemilik yayasan harus segera melakukan penyesuaian terhadap aset yayasan yang dimilikinya. Rumusan masalah dalam penelitian ini adalah mengenai akibat hukum kedudukan hak pakai sebagai aset yayasan pada yayasan yang belum disesuaikan berdasarkan UndangUndang Yayasan dan penyelesaian terhadap aset yayasan Dewantara Ciptasari. Metode pendekatan yang digunakan dalam penelitian ini adalah metode pendekatan yuridis normative. Hasil penelitian ini adalah Akibat Hukum dari Kedudukan Hak Pakai Sebagai Aset Yayasan Pada Yayasan Yang Belum Disesuaikan Berdasarkan Undang-Undang Yayasan akan mengakibatkan tidak diakuinya badan hukum dari yayasan yang belum didaftarkan asetnya.
\end{abstract}

Kata Kunci : yayasan, aset, penyesuaian 


\title{
POSITION OF ASSETS FROM FOUNDATION NOT POST ADEQUATE POST OF THE LAW NUMBER 28 YEAR 2004 CONCERNING AMENDMENT TO LAW OF NUMBER 16 YEAR 2001
}

\author{
Mustofa Mustofa \\ Master of Law, University of Semarang
}

\begin{abstract}
This study aims to analyze the assets that have not been adjusted after the issuance of the latest regulations regarding the foundation. The existence of the foundation in Indonesia has full strength with the existence of the Law of the Foundation that is Law Number 28 Year 2004. This raises everything related to the assets of the foundations both material and immateril must be in accordance with applicable provisions. If not adjusted, the foundation does not recognize that has been established, so the owner of the foundation should immediately make adjustments to the assets of the foundation owned. The formulation of the problem in this research is about the effect of the law on the right of use as the foundation's asset to the unconstituted foundation based on the Foundation Law and the settlement against the assets of the Foundation of the province. Approach method used in this research is normative juridical approach method. The results of this study are the effect of the status of the right to use as an asset of the foundation on the unadjusted foundation based on the foundation law will result in the non-recognition of a legal entity from a foundation that has not been registered assets.
\end{abstract}

Keywords: Foundation; assets; adjustment 


\section{A. PENDAHULUAN}

Yayasan adalah badan hukum yang terdiri atas kekayaan yang dipisahkan dan diperuntukkan untuk mencapai tujuan tertentu di bidang sosial, keagamaan, dan kemanusiaan, yang tidak mempunyai anggota. Undang-Undang yang mengatur tentang Yayasan adalah Undang-Undang Nomor 28 Tahun 2004 tentang Perubahan Atas Undang-Undang Nomor 16 Tahun 2001 tentang Yayasan. Undang-Undang Nomor 28 Tahun 2004 tentang Perubahan Atas Undang-Undang Nomor 16 Tahun 2001 tentang Yayasan, memerlukan suatu aturan tentang pelaksanaannya, maka dibentuklah Peraturan Pemerintah Republik Indonesia Nomor 63 Tahun 2008 tentang Pelaksanaan Undang-Undang tentang Yayasan. ${ }^{1}$

Yayasan yang telah ada sebelum lahirnya Undang-Undang Nomor 16 Tahun 2001 sebagaimana diubah dengan Undang-Undang Nomor 28 Tahun 2004 tentang Yayasan harus disesuaikan anggaran dasarnya terlebih dahulu dan diajukan pengesahannya sebagai badan hukum yayasan kepada menteri. Penyesuaian anggaran dan pengajuan pengesahan kepada menteri wajib dilakukan, apabila hal ini tidak dilakukan maka sesuai dengan ketentuan peralihan pasal 71 ayat (4) Undang Undang nomor 28 Tahun 2004 perubahan atas Undang-Undang nomor 16 tahun 2001 tentang Yayasan maka yayasan tidak boleh menggunakan kata "Yayasan" di depan namanya, akan hilang kewenangannya sebagai badan hukum dan dapat dibubarkan dengan putusan pengadilan atas permohonan kejaksaan atau pihak yang berkepentingan.

Pemindahan hak atas kekayaan Yayasan harus memperhatikan ketentuan yang diatur di dalam Undang-Undang Nomor 28 tahun 2004. Prinsipnya berdasarkan ketentuan yang diatur dalam UU Yayasan, pemindahan hak atas kekayaan Yayasan dilakukan oleh Pengurus Yayasan dengan persetujuan dari Pembina Yayasan. Syarat dan ketentuan lainnya berkaitan dengan hal tersebut harus memperhatikan lebih lanjut ketentuan yang ada dalam Anggaran Dasar

${ }^{1}$ Chatamarassjid, SH, MH, Tujuan Sosial Yayasan dan Kegiatan Usaha Bertujuan Laba, (Bandung: PT. Citra Aditya Bhakti, 2000), hlm. 5 
Yayasan misalnya siapa yang berwenang mewakili Pengurus dan bagaimana bentuk persetujuan yang diberikan oleh Pembina.

Pasal 5 Undang-Undang Nomor 28 Tahun 2004 disebutkan bahwa Kekayaan Yayasan baik berupa uang, barang, maupun kekayaan lain yang diperoleh Yayasan berdasarkan Undang-Undang ini, dilarang dialihkan atau dibagikan secara langsung atau tidak langsung, baik dalam bentuk gaji, upah, maupun honorarium, atau bentuk lain yang dapat dinilai dengan uang kepada Pembina, Pengurus, dan Pengawas.

Larangan untuk mengalihkan kekayaan Yayasan kepada pihak lain maka pada prinsipnya hal tersebut boleh dilakukan. Namun, pengalihan kekayaan Yayasan kepada pihak lain tersebut disamping harus memperhatikan syarat formalitas yang ditetapkan dalam UU Yayasan dan Anggaran dasar Yayasan, misalnya harus meperoleh persetujuan dari Dewan Pembina, juga haruslah memperhatikan prinsip-prinsip dan ketentuan-ketentuan yang terdapat di dalam UU Yayasan serta Anggaran Dasar. Prinsip dan ketentuan utama yang harus diperhatikan adalah prinsip yang terdapat di dalam Pasal 26 ayat 4 UU Yayasan, yang menetukan "Kekayaan Yayasan ... dipergunakan untuk mencapai maksud dan tujuan Yayasan."

\section{B. PERMASALAHAN}

Atas dasar latar belakang tersebut di atas, maka yang menjadi perumusan masalah adalah sebagai berikut :

1. Bagaimana kedudukan aset dari yayasan yang belum disesuaikan menurut Undang-Undang Yayasan?

2. Bagaimana penyelesaian terhadap aset yayasan Dewantara Ciptasari Slawi menurut Undang-Undang Yayasan (Kajian Hukum Putusan Pengadilan Negeri Slawi No. 16/Pdt.P/2015/PN Slw)? 


\section{METODE PENELITIAN}

Penelitian ini menggunakan metode pendekatan yuridis normatife atau hukum normatif. Metode penelitian ini merupakan metode penelitian hukum kepustakaan dimana metode atau cara yang dipergunakan di dalam penelitian hokum dilakukan dengan cara meneliti bahan pustaka yang ada. ${ }^{2}$ Tahapan pertama penelitian hukum normatif adalah penelitian yang ditujukan untuk mendapatkan hukum obyektif (norma hukum), yaitu dengan mengadakan penelitian terhadap masalah hukum. Tahapan kedua penelitian hukum normatif adalah penelitian yang ditujukan untuk mendapatkan hukum subjektif (hak dan kewajiban). ${ }^{3}$

Relevansi pendekatan penelitian ini adalah untuk menganalisis dan mengkaji kedudukan aset dari yayasan yang belum disesuaikan menurut UndangUndang Nomor 28 Tahun 2004 Tentang Yayasan (Kajian Hukum Putusan Pengadilan Negeri Slawi No. 16/Pdt.P/2015/PN Slw).

\section{PEMBAHASAN}

\section{Kedudukan Aset Dari Yayasan Yang Belum Disesuaikan Menurut Undang-Undang Nomor 28 Tahun 2004 Tentang Yayasan}

Perubahan Undang-Undang Yayasan sesuai dengan konsideran UndangUndang No. 28 Tahun 2004 disebabkan karena Undang-Undang No. 16 Tahun 2001 dalam perkembangannya belum menampung seluruh kebutuhan dan perkembangan hukum dalam masyarakat, serta terdapat beberapa substansi yang dapat menimbulkan berbagai penafsiran.

Yayasan yang sebelumnya ada dinyatakan tetap diakui sebagai badan hukum, apabila dalam waktu paling lambat 3 (tiga) tahun sejak mulai berlakunya UndangUndang Yayasan. Yayasan dengan kategori tersebut wajib menyesuaikan Anggaran Dasarnya dengan Undang-Undang Yayasan.

\footnotetext{
${ }^{2}$ Soerjono Soekanto dan Sri Mamudji, Penelitian Hukum Normatif Suatu Tinjauan Singkat, Cetakan ke-11, (Jakarta, PT Raja Grafindo Persada, 2009), hlm. 13-14

${ }^{3}$ Hardijan Rusli, 2006, Metode Penelitian Hukum Normatif, Bagaimana, (Law Review Fakultas Hukum Universitas Pelita Harapan, Volume V No. 3 Tahun, hlm. 50.
} 
Ketentuan pasal 71 ayat (4) Undang-Undang Yayasan, menyatakan bahwa Yayasan yang tidak menyesuaikan Anggaran Dasarnya dalam jangka waktu sebagaimana dimaksud pada ayat (1) dan yayasan sebagaimana dimaksud pada ayat (2), tidak dapat menggunakan kata yayasan di depan namanya dan dapat dibubarkan berdasarkan keputusan Pengadilan atas permohonan Kejaksaan atau pihak yang berkepentingan.

Bagi Yayasan yang hendak mengalihkan aset yayasan kepada pihak ketiga tetapi yayasan tersebut belum melakukan penyesuaian terhadap Undang-Undang Yayasan wajib melakukan penyesuaian sebelum melakukan pengalihan aset kepada pihak luar, dengan memperhatikan beberapa persyaratan yang telah ditetapkan oleh Undang-Undang Yayasan, untuk mendukung maksud dan tujuan dari Yayasan tersebut, para Pengurus dari Yayasan tersebut sepakat untuk menjual asset yayasan kepada pihak ketiga, sesuai yang tercantum dalam pasal 37 Undang-Undang Yayasan No. 16 Tahun 2001 sebagaimana di ubah dengan Undang-Undang No.28 Tahun 2004 Tentang Yayasan yang menyebutkan bahwa Pengurus tidak berwenang mengalihkan kekayaan Yayasan kecuali dengan persetujuan Pembina.

\section{Penyelesaian Terhadap Aset Yayasan Dewantara Ciptasari Slawi Menurut} Undang-Undang Nomor 28 Tahun 2004 Tentang Yayasan (Kajian Hukum Putusan Pengadilan Negeri Slawi No. 16/Pdt.P/2015/PN Slw)

Terbitnya Peraturan Pemerintah No.63 Tahun 2008 ternyata peraturan tersebut belum dapat secara tuntas menyelesaikan permasalahan yang dihadapi oleh yayasan-yayasan yang sudah lahir sebelum Undang-Undang Yayasan karena sampai dengan saat sebelum lahirnya Peraturan Pemerintah No.2 Tahun 2013 banyak yayasan-yayasan yang lahirnya sebelum Undang-Undang Yayasan yang tetap melakukan kegiatan-kegiatannya, tetapi secara kelembagaan yayasan tersebut sudah tidak eksis lagi karena tidak melaksanakan penyesuaian dan 
melaporkan kepada Menteri sebagaimana diminta oleh Undang-Undang maupun Peraturan Pemerintah Nomor 63 Tahun 2008. ${ }^{4}$

Yayasan seperti itu dapat disebut sebagai Yayasan yang tidak pernah menyesuaikan angg aran dasarnya atau Yayasan yang mati suri tidak harus di likuidasi tapi Yayasan tersebut dapat dihidupkan kembali berdasarkan Peraturan Pemerintah Nomor 2 Tahun 2013 Tentang Perubahan Atas Peraturan Pemerintah No.63 Tahun 2008 Tentang Pelaksanaan Undang-Undang Tentang Yayasan.

Penelitian penulis terkait hak pakai aset yayasan pada yayasan yang belum disesuaikan adalah penetapan Pengadilan Negeri Slawi No. 16/Pdt.P/2015/PN Slw. Prof. Dr. Pudjo Nirmolo dan Ir. Atma Windrija merupakan pengurus serta mewakili kepentingan Yayasan Dewantara Ciptasari beralamat di Jalan KH. Ahmad Dahlan Blok B RT. 004, RW. 001 Desa Slawi Kulon Kecamatan Slawi Kabupaten Tegal. Keduanya adalah para pemohon dengan surat Permohonannya tertanggal 2 Maret 2015 yang diterima dan didaftar di Kepaniteraan Pengadilan Negeri Slawi pada tanggal 2 Maret 2015 dengan register Nomor : 16/Pdt.P/2015/PN.Slw. telah mengajukan permohonan kepada Pengadilan Negeri.

Peraturan Pemerintah nomor 2 tahun 2013 mempunyai fungsi untuk memberikan kemungkinan bagi yayasan-yayasan yang semula sudah tidak ada lagi secara kelembagaan masih dimungkinkan kembali untuk melakukan penyesuaian anggaran dasarnya. Peraturan ini berlaku khusus untuk kepentingan yayasan yang lahir sebelum terbitnya Undang-Undang Yayasan yang belum sempat melakukan penyesuaian atau melaporkan kepada menteri dan yayasan yang tidak diakui sebagai badan hukum agar dapat eksis kembali secara kelembagaan.

Proses pemindahan hak atas kekayaan Yayasan harus memperhatikan ketentuan yang diatur di dalam UU Nomor 16 tahun 2001 sebagaimana diubah dengan UU Nomor 28 tahun 2004 ("UU Yayasan"). Prinsipnya berdasarkan

\footnotetext{
${ }^{4}$ Henricus Subekti, Mulyoto, Op.Cit, halaman 5
} 
ketentuan yang diatur dalam UU Yayasan, pemindahan hak atas kekayaan Yayasan dilakukan oleh Pengurus Yayasan dengan persetujuan dari Pembina Yayasan. Syarat dan ketentuan lainnya berkaitan dengan hal tersebut harus memperhatikan lebih lanjut ketentuan yang ada dalam Anggaran Dasar Yayasan, misalnya siapa yang berwenang mewakili Pengurus dan bagaimana bentuk persetujuan yang diberikan oleh Pembina. ${ }^{5}$

\section{E. PENUTUP}

Kedudukan Aset Dari Yayasan Yang Belum Disesuaikan Menurut UndangUndang Nomor 28 Tahun 2004 Tentang Yayasan yaitu sebagaimana yang tertuang dalam pasal 899, 900, 1680 dan Pasal 365 K.U.H. Perdata, kemudian dalam Pasal 6 ayat 3 dan Pasal 236 Rv. Penyesuaian hak pakai sebagai aset yayasan merupakan syarat yang mutlak yang harus dilakukan oleh Yayasan yang didirikan sebelum Undang-Undang Yayasan no. 28 Tahun 2004. Landasan hukumnya tidak begitu jelas, karena belum ada aturannya secara tertulis. Sifat tertutup tersebut terasa di kalangan masyarakat karena masyarakat pada umumnya tidak dapat mengetahui tentang struktur organisasi suatu yayasan dan organ yayasan itu. Kemudian, dari segi administrasi pendaftaran, tidak ada kewajiban bagi yayasan untuk melakukan pendaftaran ke salah satu instansi pemerintah, sehingga pihak pemerintah tidak dapat melakukan pengawasan terhadap setiap kegiatan yang dilakukan oleh Yayasan. Ditinjau dari aset yayasan pada saat itu belum ada kejelasan, baik dalam proses pencarian dana maupun penggunaan hak pakai untuk kepentingan yayasan dan bagaimana pengurus mempertanggung jawabkan keuangan yayasan untuk setiap tahunnya.

Proses penyelesaiannya terhadap kedudukan aset dari yayasan yang belum disesuaikan menurut Undang-Undang Nomor 28 Tahun 2004 tentang yayasan (Kajian Hukum Putusan Pengadilan Negeri Slawi No. 16/Pdt.P/2015/PN Slw). Terbitnya Peraturan Pemerintah No. 2 Tahun 2013 merupakan kesempatan bagi Yayasan yang selama ini belum menyesuaikan. Untuk proses permohonan

\footnotetext{
${ }^{5}$ http://alwesius.blogspot.co.id/2011/12/pemindahan-hak-atas-kekayaan-yayasan.html diakses tanggal 20 November 2017
} 
e-ISSN : 2621-4105

penyesuaian dan pengesahannya, pengurus Yayasan Dewantara Ciptasari Slawi mengajukan bukti-bukti agar Pengadilan Negeri menetapkan Yayasan Dewantara Ciptasari sebagai kelanjutan dan penerus sah dari Yayasan Dewantara Foundation serta memberi ijin kepada Para Pemohon/Pengurus Yayasan Dewantara Ciptasari untuk pengurusan aset milik Yayasan Dewantara Foundation atas Tanah bekas Hak Pakai Nomor : 1/Bandarjo. 


\section{DAFTAR PUSTAKA}

\section{Buku}

Adjie, Habib dan Nuhamad Hafid, 2013, Kompilasi Peraturan PerundangUndangan Yayasan, Pustaka Zaman, Semarang.

Ali, Chaidir, 1987, Badan Hukum, Alumni, Jakarta.

Ais, Cartamarasdjid, 2000, Tujuan sosial Yayasan dan Kegiatan Usaha Bertujuan Laba, PT. Citra Aditya Bakti, Bandung.

Barron, Margaret L., 1992, Fundamentals of Busenness law, McGraw-Hill Book Company Australia Pty Limited, Australia.

Denim, Sudarwan, 2002, Menjadi Peneliti Kualitatif, Pustaka Setia, Bandung.

Harsono, Boedi, 2008, Hukum Agraria Indonesia Sejrah Pembentukan UndangUndang Pokok Agraria, Isi dan Pelaksanaannya Jilid 1Hukum Tanah Nasional, Djembatan, Jakarta.

Komariah, 2002, Hukum Perdata, UMM Press, Malang.

Komaruddin dan Yooke Tjumparmah, 2000, Kamus Istilah Karya Tulis Ilmiah, Bumi Askara, Jakarta.

Malik, Rusdi, 2000, Penemu Agama Dalam Hukum di Indonesia, Untiversitas Trisakti, Jakarta.

Mudjiono, 1992, Hukum Agraria, Liberty, Yogyakarta.

Natzir, Said, 1987, Hukum Perusahaan Indonesia 1 (Perorangan), Alumni, Bandung.

ND, Mukti Fajar dan Yulianto Achmad, 2010, Dualisme Penelitian Hukum Normatif dan Empiris, Pustaka Pelajar, Yogyakarta.

Prasetya, Rudi dan Oemar Wongsodiwiryo, 1976, Dasar-Dasar Hukum Persekutuan, Departemen Hukum Dagang Fakultas Hukum Airlangga, Surabaya.

Rasjid, Chatama, 2001, Tujuan Sosial Yayasan dan Kegiatan Usaha Bertujuan Laba, Cet. I, Citra Ditya Bakti, Bandung.

Soekanto, Soerjono, 1986, Pengantar Penelitian Hukum, UI Press, Jakarta.

Soekanto, Soerjono dan Sri Mamudji, 2009, Penelitian Hukum Normatif Suatu Tinjauan Singkat, Cetakan ke-11, PT Raja Grafindo Persada, Jakarta.

Soeroedjo, Hayati, 1981, Status Hukum Yayasan Dalam Kaitannya Dengan Penataan Badanbadan Usaha di Indonesia, Makalah, Jakarta.

Sukayadi, HMN Kusworo, 2007, Pengelolaan Tanah Negara, STPN Press, Yogyakarta.

Sutedi, Adrien, 2011, Sertifikat Hak Atas Tanah, Sinar Grafika, Jakarta.

Wargakusumah, Hasan, 1995, Hukum Agraria, P.T Gramedia Pustaka Utama, Jakarta. 


\section{Jurnal}

Rusli, Hardijan, 2006, Metode Penelitian Hukum Normatif, Bagaimana, (Law Review Fakultas Hukum Universitas Pelita Harapan, Volume V No. 3.

\section{Undang-Undang}

Undang-Undang Nomor 28 Tahun 2004 tentang Perubahan Atas Undang- Undang Nomor $16 \quad$ Tahun 2001 tentang Yayasan,

Staatsblad 1870 No. 64 Tentang Perkumpulan

Peraturan Pemerintah nomor 24 tahun 1997 tentang Pendaftaran Tanah.

Peraturan Pemerintah nomor 40 tahun 1996 Tentang Hak Guna Usaha, Hak Guna Bangunan dan Hak Pakai Atas Tanah

\section{Internet}

Adjie, Habib, Menghidupkan Yayasan Mati Suri, http:// www.indonesianotarycommunity.com/menghidupkan-yayasan-mati-suri/

Alwesius, Pemindahan Hak Atas Kekayaan Yayasan, http: //alwesius.blogspot.co.id/

Dwi, Setyo, Tujuan Hukum Menurut Gustav Radbruch, https://bolmerhutasoit.wordpress.com/2011/10/07/artikel-politik-hukumtujuan-hukum-menurut-gustav-radbruch/

Sova, Sakhiyatu, Tiga Nilai Dasar Hukum Menurut Gustav Radbruch, http://www.scribd.com/doc/170579596/Tiga-Nilai-Dasar-Hukum Menurut-Gustav- Radbruch\#scribd 